\title{
THE LEAST-COST OPTIMIZATION OF PV-STATION DC/AC EQUIPMENT USING BATTERY ENERGY STORAGE SYSTEM
}

\author{
I. Buratynskyi*, T. Nechaieva \\ Institute of General Energy of the National Academy of Sciences of Ukraine, \\ 172 Antonovycha Str., Kyiv, 03150, UKRAINE \\ *e-mail: buratunsky@gmail.com
}

The auction allocation of state support quotas for renewable generation implementation that will change the existing incentive for their development by providing "green" tariffs to producers is based on competitive selection of the power plant projects with the least cost of electricity generation. The competitive advantage of solar photovoltaic power plant (PV stations) projects can be done by deciding what kind of equipment can provide the minimum cost of electricity generation during the period of operation. In the article, there is improvement of non-linear mathematical least-cost optimization model of the structure of PV-station equipment using DC coupled battery energy storage system (BESS) to store the excess electricity of photovoltaic modules (PV modules), which is lost on inverters when they are overloaded during the hours of the highest intensity of solar radiation. The article presents the modelling results of overall operation of PV station with fixed power of PV modules, as well as determines optimal power of inverter equipment and battery capacity. The model calculations have shown that when the DC equipment costs of the PV station are reduced by almost $62 \%$ and DC equipment costs of BESS are reduced by $86.7 \%$ of the actual value in 2020 at the power of $10 \mathrm{MW}$ PV modules, the optimal power of inverter equipment decreases from 7.08 to 6.29 MW, and the storage capacity increases from 0.22 to $2.51 \mathrm{MWh}$. The use of BESS allows accumulating the amount of electricity produced by PV modules, which is lost with limitation on inverters, while the cost of their joint electricity production is decreased by $0.42 \%$.

Keywords: BESS, DC/AC overloading, levelized daily cost of electricity, nonlinear modelling, optimization, PV station. 
In recent years, in Ukraine and in the world there is a sharp increase in the installed capacities of renewable energy source (RES) generation. It is related to the fact that the countries of the world are willing to promote sustainable development with the transition to the "green" clean energy in order to achieve global climate goals of the Paris Agreement. According to the target indicators of the Energy Strategy of Ukraine [1], the development of generating capacities in the period from 2020 to 2035 has to increase the share of RES in the total electricity production from $7 \%$ to $25 \%$.

Among all the RES, PV stations have the highest rate of implementation. It is due to the rapid development of this sector, because the PV equipment and the design of power plants are improved on a regular basis. PV modules become more powerful and efficient every year and their cost falls sharply.

In Ukraine, the legislative incentive for implementation of RES generation by providing high "green" tariffs brought about a high increase in the installed capacity of PV stations. As of the end of 2020, their total power was $5.36 \mathrm{GW}$, which was $9.8 \%$ of the total Integrated Power System (IPS) of Ukraine capacity; compared to 2019, it was $3.56 \mathrm{GW}(6.7 \%)$ and in $2018-1.22 \mathrm{GW}$ $(2.5 \%)[2]$.

Along with such a rapid development, there is a number of problems related to further implementation of PV stations in Ukraine. Due to the specifics of PV stations to generate maximum power at noon and overall reduction of electricity consumption from the beginning of 2020 in IPS of Ukraine, the government is forced to introduce dispatch restrictions on power plants, including PV stations. This is due to insufficient flexibility of IPS of Ukraine with a significant share of baseload capacity.

High "green" tariffs for the RES producers, imperfect payments for electricity on the new electricity market have led to considerable debt and the need to take special measures in order to reduce these tariffs.

To overcome the non-payment crisis and to achieve the compliance of variable RES generation amount with the power system capabilities at the legislative level, new competitive conditions for auction allocation of quotas for their construction have been adopted since 2019. The main aim of capacity distribution is to reduce the cost of electricity generated by RES. The quotas will be distributed among those auction participants who will offer the lowest prices for the sale of electricity, which will be guaranteed to be paid to the producer.

Due to lower costs for implementation and maintenance of BESS to provide for more stable operation of power plants, their joint use with PV station is becoming more common.

The location of BESS at the site of the PV station as part of it has many advantages, because in this case there is no need to allocate a separate land plot and to obtain permits for construction. When BESS operates together with the PV station, there is no need to install additional equipment, because it is possible to share power transformers, electricity transmission lines and other equipment. In general, the total costs when installing BESS at the site of the PV station, as it is defined in the study related to cost indicators for the photovoltaic systems and the electricity storage systems [3], are $7-8 \%$ lower than when they are located separately. 
Based on the size of the land for the construction of the PV station, the investor, focusing on a certain DC power of PV modules, should select AC power of the inverter equipment that will provide the lowest cost of electricity generation, which will give the corresponding benefits when participating in the auction for the allocation of quotas for the new construction of the PV station.

At present, a particularly important task is to find the ways for minimization of PV station electricity production costs. One of the methods of reducing electricity production costs is to reduce AC power of inverter equipment at a fixed power of PV modules. As the results of the study [4] show, for the 10 MW PV station, located in the south of Ukraine, the lowest cost is achieved with $\mathrm{DC} / \mathrm{AC}$ ratio of 1.4. At the same time, when the inverters are overloaded with excess power of PV modules, part of electricity that has to be output to power system is lost.

The aim of the study is to model an optimal least-cost structure of the PV station equipment using BESS in order to accumulate and output excess power of PV modules, which is lost with limitations on inverters.

\section{THEORY}

Nonlinear mathematical model of optimization of the PV station equipment structure [5] provides the choice of optimal AC power of inverter equipment with fixed DC power of PV modules to achieve the minimal cost of electricity generation during their lifetime depending on the intensity of solar radiation. The performed model calculations [5] showed the difference in the structure of PV station equipment for sunny and cloudy days at different levels of solar radiation. It means that the optimal structure of the PV station equipment is formed according to its geographical location, which is an important factor for the selection of equipment before the stage of participation in the auction for the allocation of quotas for installed capacity.

Further improvement of nonlinear mathematical model of optimising the PV station equipment structure was conducted to determine the structure of PV station equipment using BESS for storage and output of the excess power of PV modules with DC/AC overloading, which was lost on inverters, the joint operation of which would provide for the minimal cost of out- put electricity.

There are two main ways to connect BESS to PV station: AC coupled and DC coupled, each of them having its advantages and disadvantages. During construction of new power plants, it is better to use a DC coupled approach because in this case saving of generated and output electricity is from 1 to $4 \%$ with joint operation of PV station and BESS as it is shown in the paper [6].

The joint operation of PV station and BESS means to connect batteries to the same busbars close to the central inverters together with PV modules. In this study, connection of BESS to PV station is done using a DC coupled approach. The simplified structure diagram is shown in Fig. 1. 


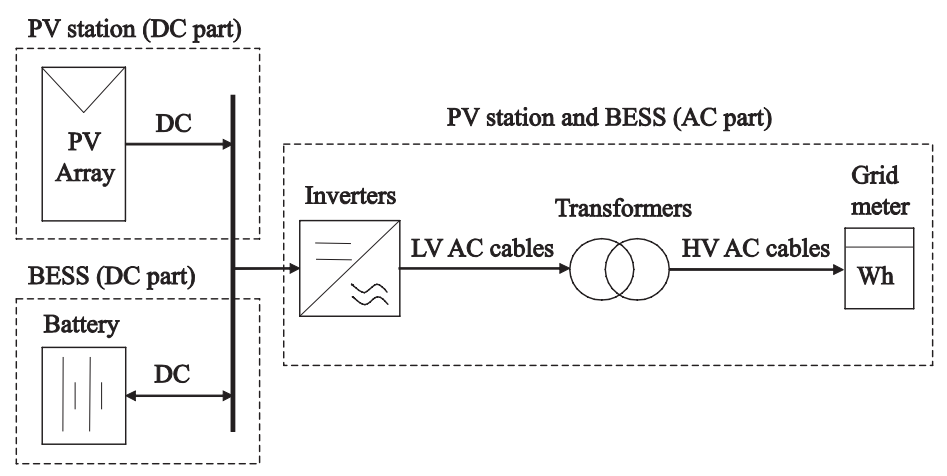

Fig. 1. The simplified structure diagram of PV station and BESS.

The objective function of the improved model is to minimise the levelized daily cost of electricity generation (LDCOE) with the joint operation of PV station and the use of BESS in the saving mode of losses of electric power of PV modules on inverters during their overloading. The total excess of PV module capacity, which is in excess of PV station inverter capacity, is accumulated in batteries with subsequent discharge during the day.
LDCOE is determined by the ratio of the capital investment costs during implementation and the summary of operational costs during the whole period of PV station and BESS operation lifetime, which are reduced to the weighted daily average and to daily volumes of output electricity during the joint operation of PV station and BESS taking into consideration the level of solar radiation.

$L D C O E=\frac{P^{D C}\left(c^{D C}+o^{D C}\right)+P^{D C} x^{A C / D C}\left(c^{A C}+o^{A C}\right)+E^{B E S S} / \eta^{R T}\left(c^{B E S S}+o^{B E S S}\right)}{E^{P V}+E^{B E S S} \eta^{R T}} \rightarrow \min$,

where $L D C O E$ is levelized daily cost of electricity when PV station and BESS operate together in the mode of saving electricity losses on inverters during their overloading, $\$$ / MWh; $P^{D C}$ is installed DC power of PV modules, MW; $x^{A C / D C}$ is variable AC/DC ratio (inverse coefficient to DC/AC ratio); $c^{D C}$ is specific daily capital expenditure (CAPEX) for DC power, $\$ / \mathrm{MW} ; O^{D C}$ is specific daily operational expenditure (OPEX) for DC power, $\$ /$ MW; $c^{A C}$ is specific daily CAPEX for AC power, $\$ / \mathrm{MW} ; O^{A C}$ is specific daily OPEX for $\mathrm{AC}$ power, $\$ / \mathrm{MW} ; E^{B E S S}$ is excess electrical energy on inverters during overloading that accumulates in BESS, MWh; $\eta^{R T}$ is round trip efficiency (RT) of BESS, share; $c^{B E S S}$ is specific daily CAPEX for BESS, \$/MWh; $o^{B E S S}$ is specific daily OPEX for BESS, \$/MWh; $E^{P V}$ is generated electricity at the PV station and outputed into the power system, MWh.

The $\mathrm{AC} / \mathrm{DC}$ variable ratio is determined as follows:

$x^{A C / D C}=\frac{X^{A C}}{P^{D C}}$,

where $X^{A C}$ is variable installed AC power of inverters, MW.
For the variable power ratio of alternating and direct current PV station in the model, the following restriction is set:

$$
0.5<x^{A C / D C} \leq 1 \text {. }
$$

The electrical energy output from the $\mathrm{PV}$ station to the power system is deter- 
mined according to the intensity of solar radiation entering the $\mathrm{PV}$-modules, taking into account the power limit of inverters [5]:

$E^{P V}=\sum_{t=1}^{T} P_{t}^{\text {PVout }} \cdot \Delta t$

where $T$ is the number of measurement intervals in one day (for hourly schedule $T=24) ; P^{P V o u t}{ }_{t}$ is the value of the genera- tion power at the PV station, which is issued to the power system during the time $t$ during the day, MW; $\Delta t$ is the duration of one time period (hour).

The power supply of electricity from the PV station to the power system during time $t$ is determined taking into account the limitation of inverter power depending on the level of solar radiation [5]:

$$
P^{\text {PVout }}{ }_{t}=\left[\begin{array}{l}
P^{D C} x^{A C / D C}, \quad P^{D C} I_{t} \geq P^{D C} x^{A C / D C} \\
P^{D C} I_{t}, \quad P^{D C} I_{t}<P^{D C} x^{A C / D C}
\end{array},\right.
$$

where $I_{t}$ is intensity of solar radiation, relative units.

Excess electrical power on inverters during overloading is the BESS charging power. Therefore, the total accumulated electricity in BESS is defined as follows:

$E^{B E S S}=\sum_{t=1}^{T} P_{t}^{B E S S c h r g} \cdot \Delta t$,

where $P^{\text {BESSchrg }}{ }_{t}$ is the BESS charging power during time $t$, MW.
BESS charging power is determined as follows:

$$
P_{t}^{B E S S c h r g}=\left[\begin{array}{l}
P^{D C} I_{t}-P^{D C} x^{A C / D C}, \quad P^{D C} I_{t} \geq P^{D C} x^{A C / D C} \\
0, \quad P^{D C} I_{t}<P^{D C} x^{A C / D C}
\end{array} .\right.
$$

OPEX of PV station and BESS during their joint work, equal to operating life for PV station, is reduced to annual levelized cost using a capital recovery factor (CRF). The total costs are considered to be evenly distributed for each day during the year.

Since the BESS is connected to the
PV station on the DC side, there is no AC component of the inverter equipment in its CAPEX and OPEX costs.

The specific levelized daily capital investment costs for PV station equipment and BESS are determined as follows [5]:

$c^{D C, A C, B E S S}=\left(i^{D C, A C, B E S S}+k^{D C, A C, B E S S}\right) \cdot C R F / 365$,

where $i^{D C, A C, B E S S}$ is specific capital costs for $\mathrm{PV}$ station (\$/MW) and BESS (\$/MWh); $k^{D C, A C, B E S S}$ is specific discounted interest payments on loans (\$/MW; $\$ / \mathrm{MWh}) ; C R F$ is capital recovery factor; 365 is the number of days per year. 
$i^{D C, A C, B E S S}=e^{D C, A C, B E S S}\left(1+E P C^{D C, A C, B E S S}\right)$,

where $e^{D C, A C, B E S S}$ is specific costs on equipment (\$/MW; $\left.\$ / \mathrm{MWh}\right) ; E P C^{D C, A C, B E S S}$ is share of costs on engineering, procurement and construction (EPC) from CAPEX.

Specific discounted interest payments on loans are determined as follows [5]:

$k^{D C, A C, B E S S}=\sum_{t=T^{E P C}}^{m} \frac{c^{K}{ }_{t}}{(1+r)^{t-T^{E P C}-1}}$,

where $c^{K}{ }_{t}$ is specific annual interest payments on loans attracted for investment
(\$/MW; \$/MWh); $T^{E P C}$ is years of EPC for $\mathrm{PV}$ station and BESS; $m$ is a loan repayment period (years); $r$ is a discount rate, $\%$.

Specific levelized daily OPEX for DC and $\mathrm{AC}$ equipment of PV station and BESS is determined as follows:

$o^{D C, A C, B E S S}=\sum_{n=1}^{N} \frac{O M^{D C, A C, B E S S}}{(1+r)^{n-1}} \cdot C R F / 365$.

where $O M^{D C, A C, B E S S}$ is annual specific costs for operation and maintenance (O\&M) for DC and $\mathrm{AC}$ equipment of PV station and BESS, $\$ / \mathrm{MWh} ; n$ is the current year of operation; $N$ is the number of years of joint operation of PV station and BESS.

\section{RESULTS AND DISCUSSION}

10 MW DC power PV station, which is located close to the geographical centre of Ukraine in Cherkasy region, was chosen for the model calculations. The data on intensity of solar radiation were used from online resource PVGIS [7]. To study the territory, average data were received on intensity of solar radiation by the average value during the year.

Table 1 shows the technical and economic indicators used in the LDCOE calculations.

Table 1. Technical and Economic Data for Modelling

\begin{tabular}{|l|l|c|c|}
\hline No & Indicator & Unit & Value \\
\hline 1 & Discount rate & $\%$ & 10.7 \\
\hline 2 & Share of investment costs covered by external loan & $\%$ & 70 \\
\hline 3 & Interest rate & years & 10.4 \\
\hline 4 & Loan repayment period & MW $_{\text {DC }}$ & 10 \\
\hline 5 & Installed DC power of PV modules & years & 20 \\
\hline 6 & Operating lifetime of PV station and BESS & years & 1 \\
\hline 7 & Construction period of PV station and BESS & $\%$ & 14.0 \\
\hline 8 & Share of EPC costs of PV station equipment costs & $\%$ & 11.2 \\
\hline 9 & Share of EPC costs of BESS equipment costs & $\%$ & 95.0 \\
\hline 10 & Round trip efficiency of BESS & & \\
\hline
\end{tabular}


The CAPEX inputs for PV station given in the study about the future utility-scale PV LCOE until 2050 in several European countries [8] were used to conduct simulation. They are taken into account as costs of DC equipment. Input costs are converted from euro into dollars according to the exchange rate of 1.24. The specific cost of AC equipment is $215 \$ / \mathrm{kW}$ with a similar trend going down in the coming years. OPEX inputs are taken from the study [8] with the breakdown in the percentage of costs for DC and AC equipment as $70 \%$ and $30 \%$, respectively.

The data on CAPEX for DC equipment of BESS, the main component of which is batteries, are taken from Bloomberg NEF
[9] and additional costs at the level of $9.5 \%$ are taken into account to provide their normal functioning (HVAC, lighting, fire protection system, software, etc.). OPEX costs for DC equipment of BESS are taken as part of the costs at the level of $77 \%$ from the study [8]. Other costs (23\%) are not taken into account because it is assumed that these are the costs for BESS AC equipment, which are absent in case of a DC coupled approach.

Table 2 shows the accepted input parameters and the obtained results of model calculations of the optimal DC/AC ratio of $\mathrm{PV}$ modules and inverter equipment PV station with BESS and without BESS.

Table 2. Input Data and Optimization Results

\begin{tabular}{|c|c|c|c|c|c|c|}
\hline No & Indicator name & Unit & 2020 & 2030 & 2040 & 2050 \\
\hline & \multicolumn{6}{|l|}{ Input data for PV station (DC part) } \\
\hline 1.1 & Specific CAPEX & $\$ / \mathrm{kW}$ & 534.0 & 341.0 & 253.0 & 203.0 \\
\hline 1.2 & Specific OPEX & $\$ / \mathrm{kW} / \mathrm{a}$ & 7.6 & 5.6 & 4.3 & 3.6 \\
\hline 1.3 & Specific daily CAPEX & $\$ / \mathrm{kW}$ & 204.2 & 139.0 & 109.3 & 92.6 \\
\hline \multirow[t]{2}{*}{1.4} & Specific daily OPEX & $\$ / \mathrm{kW}$ & 60.3 & 47.1 & 40.6 & 36.9 \\
\hline & \multicolumn{6}{|l|}{ Input data for PV station (AC part) } \\
\hline 2.1 & Specific CAPEX & $\$ / \mathrm{kW}$ & 215.0 & 137.0 & 102.0 & 82.0 \\
\hline 2.2 & Specific OPEX & $\$ / \mathrm{kW} / \mathrm{a}$ & 3.3 & 2.4 & 1.9 & 1.6 \\
\hline 2.3 & Specific daily CAPEX & $\$ / \mathrm{kW}$ & 82.1 & 55.9 & 44.0 & 37.2 \\
\hline \multirow[t]{2}{*}{2.4} & Specific daily OPEX & $\$ / \mathrm{kW}$ & 17.9 & 12.5 & 9.8 & 8.3 \\
\hline & \multicolumn{6}{|l|}{ Input data for BESS (DC part) } \\
\hline 3.1 & Specific CAPEX & $\$ / \mathrm{kWh}$ & 150.0 & 62.0 & 41.0 & 20.0 \\
\hline 3.2 & Specific OPEX & $\$ / \mathrm{kWh} / \mathrm{a}$ & 3.7 & 2.2 & 1.6 & 1.4 \\
\hline 3.3 & Specific daily CAPEX & $\$ / \mathrm{kWh}$ & 56.23 & 23.24 & 15.37 & 7.5 \\
\hline \multirow[t]{2}{*}{3.4} & Specific daily OPEX & $\$ / \mathrm{kWh}$ & 19.19 & 10.04 & 7.06 & 5.2 \\
\hline & \multicolumn{6}{|l|}{ Results } \\
\hline 4.1 & $\mathrm{DC} / \mathrm{AC}$ ratio (PV station and $\mathrm{BESS})$ & - & 1.41 & 1.41 & 1.45 & 1.59 \\
\hline 4.2 & Inverter power (PV station and BESS) & MW & 7.08 & 7.08 & 6.89 & 6.29 \\
\hline 4.3 & BESS capacity & MWh & 0.22 & 0.22 & 0.62 & 2.51 \\
\hline 4.4 & Daily energy output of PV station & MWh & 52.23 & 52.23 & 51.84 & 50.05 \\
\hline 4.5 & Daily energy output of PV station and BESS & MWh & 52.42 & 52.42 & 52.40 & 52.31 \\
\hline 4.6 & PV station in total costs & $\%$ & 20.23 & 13.21 & 11.79 & 7.37 \\
\hline 4.7 & BESS in total costs & $\%$ & 79.77 & 86.79 & 88.21 & 92.63 \\
\hline 4.8 & LDCOE of PV station & $\$ / M W h$ & 64.21 & 44.90 & 35.99 & 30.96 \\
\hline 4.9 & LDCOE of PV station and BESS & $\$ / \mathrm{MWh}$ & 64.28 & 44.87 & 35.94 & 30.83 \\
\hline 4.10 & Reduction LDCOE when using BESS & $\%$ & -0.11 & 0.07 & 0.14 & 0.42 \\
\hline
\end{tabular}


The results of the model calculations show that when the prices for batteries go down the capacity of using BESS is increasing. When the specific costs of DC equipment for the PV station decrease almost by $62 \%$ and the specific costs of DC equipment for BESS decrease by $86.7 \%$ of the actual value of 2020 , the capacity of storage increases from 0.22 to $2.51 \mathrm{MWh}$, and the optimized power of inverters reduces from 7.08 to $6.29 \mathrm{MW}$. The joint operation of the PV station and BESS in the mode of excess capacity of PV modules at the price of equipment as of 2050 provides minimum LDCOE, which is $0.42 \%$ less than LDCOE in the operation of the PV station with losses when overloaded, and the additional use of $4.3 \%$ of all the electricity supplied.

When batteries are cheaper, their use at the PV station in the mode of saving losses of excess electricity produced at the PV modules becomes increasingly cost effective. As an example to increase their profitability, it is better to send accumulated electricity from the batteries into the system when there is high demand and it is possible to sell it at a peak price.

Figure 2 shows an example of the daily schedule of the joint operation of the PV station and BESS when charging batteries during the period of maximum solar radiation according to the power limit of inverters taken into account in the optimization model. Discharge of batteries is done immediately after the end of the maximum of solar radiation according to the mathematical model of the joint operation of PV station and BESS [10], using the obtained optimization results at storage capacity of 2.51 MWh.

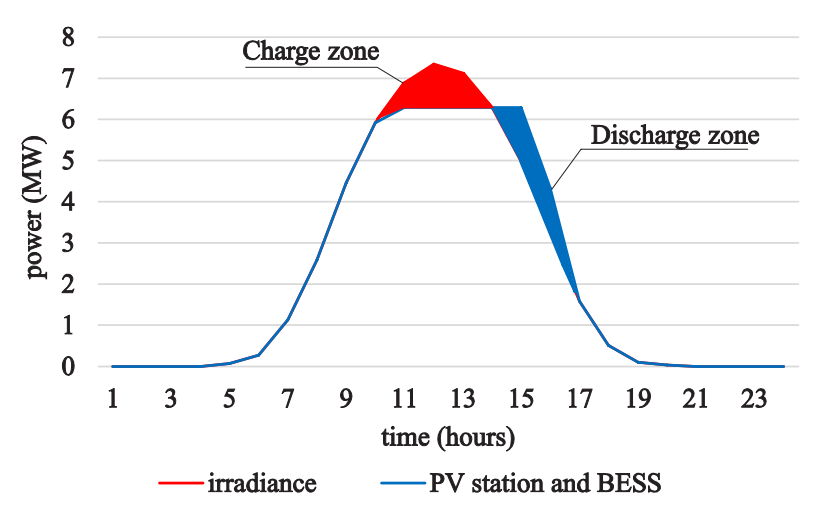

Fig. 2. The daily work schedule of joint PV station and BESS.

To save all the electricity produced by PV modules with limitations on inverters in the peak period of solar radiation, the zone of excess power of PV station is created (marked in red), which is a zone of charging batteries. The zone of battery discharge is created at once after lowering the maximum of solar radiation (marked in blue), taking into account losses during the reverse conversion of electrical energy.

\section{CONCLUSIONS}

Modern approaches to providing incentive for the development of RES by means of auction system of quota allocation for installed capacity change the approaches 
to implementation of new design for power plants. The main criterion of the auction system of quotas is to provide the electricity generation cost during the whole operational life at the lowest competitive level. Given the inexhaustible source of solar radiation for PV stations with no component of fuel consumption, it is possible to ensure minimum electricity production cost determining the optimal composition of its equipment in terms of the ratio of $\mathrm{DC}$ power of $\mathrm{PV}$ modules and $\mathrm{AC}$ power of inverter equipment.

Taking into consideration the fact that when overloaded the inverters cannot transmit all the generated electricity the restrictions are used for them. When limited, part of the generated electricity is lost. Although such measures reduce levelized cost, they also reduce the amount of electricity supplied. That is why the nonlinear mathematical model for optimization of the structure of PV station equipment is improved using BESS DC coupled to save the excess power of the PV modules when overloaded. During the joint operation of the PV station and
BESS, all the electricity generated at the PV modules, which was previously lost on the inverters when they were overloaded, is stored in the batteries and then output to the power system is provided.

Introduction of BESS in the PV station influences the optimal structure of its equipment. When the battery prices are reduced, BESS capacity, which is needed to accumulate all the excess electricity on inverters, as a result of optimization is increased, and allows reducing the power of the PV station inverters.

As the results of modelling show, taking into account the changes of the dynamics of the specific costs until 2050, for PV stations with $10 \mathrm{MW}$ PV modules the optimal power of inverters is reduced from 7.08 to $6.29 \mathrm{MW}$, and accumulation capacity increases from 0.22 to $2.51 \mathrm{MWh}$. The use of BESS allows saving around $4.3 \%$ of the total daily electricity supply, which was lost preciously due to limitations on inverters. This way the levelized daily cost of electricity is reduced by $0.42 \%$.

\section{REFERENCES}

1. Ministry of Energy of Ukraine. (2017). Energy Strategy of Ukraine for the Period up to 2035. Available at http://mpe.kmu.gov. ua/minugol/control/uk/publish/article;jses sionid $=\mathrm{B} 483 \mathrm{C} 8 \mathrm{~B} 0 \mathrm{C} 24 \mathrm{~F} 6 \mathrm{D} 22 \mathrm{E} 66 \mathrm{D} 30 \mathrm{CE}$ B3198ED5.app1?art_id=245239564\&cat_ $\mathrm{id}=245239555$

2. NPC "Ukrenergo". (2020). Installed Capacity of the IPS of Ukraine Values as of 12/2020. Available at https:// ua.energy/installed-capacity-of-the-ips-ofukraine/\#12-2020

3. Fu, R., Remo, T., \& Margolis, R. (2018). U.S. Utility-Scale Photovoltaics-PlusEnergy Storage System Costs Benchmark. Golden, CO: National Renewable Energy
Laboratory. NREL/TP-6A20-71714. Available at https://www.nrel.gov/docs/ fy19osti/71714.pdf.

4. Buratynskyi, I., Nechaieva, T., \& Shulzhenko, S. (2020). Optimization of the Equipment Structure of a Photovoltaic Solar Power Plant. The Problems of General Energy, 2 (61), 17-22. https://doi. org/10.15407/pge2020.02.017

5. Bilenko, M., Buratynskyi, I., Leshchenko, I., Nechaieva, T., \& Shulzhenko, S. (2021). Nonlinear Mathematical Model of Optimal Solar Photovoltaic Station Design. Studies in Systems, Decision and Control, 346, 49-61. https://doi.org/10.1007/978-3-03069189-9 3 
6. Walsh, D., Bradshaw, D., Clamp A., \& Russell K. (2020). Optimizing Solar PV Plus Battery Storage. Business \& Technology Surveillance. National Rural Electric Cooperative Association (NRECA).

7. Photovoltaic Geographical Information System. (PVGIS). (n.d.). Available at https://ec.europa.eu/jrc/en/pvgis

8. Vartiainen, E., Masson, G., Breyer, C., Moser, D., \& Román Medina E. (2019). Impact of Weighted Average Cost of Capital, Capital Expenditure, and Other Parameters on Future Utility-Scale PV Levelised Cost of Electricity. Prog Photovolt Res Appl, 28, 439-453. https://doi.org/10.1002/pip.3189
9. BloombergNEF. (2020). Battery Pack Prices Cited Below $\$ 100 / \mathrm{kWh}$ for the First Time in 2020, While Market Average Sits at $\$ 137 / \mathrm{kWh}$. Available at https://about.bnef. $\mathrm{com} / \mathrm{blog} /$ battery-pack-prices-cited-below100-kwh-for-the-first-time-in-2020-whilemarket-average-sits-at-137-kwh/

10. Buratynskyi, I., \& Nechaieva, T. (2020). Modeling of the Combined Operation of a Solar Photovoltaic Power Plant and a System of Electric Energy Storage. The Problems of General Energy, 3 (62), 30-36. https://doi.org/10.15407/pge2020.03.030 